\title{
IMPLEMENTASI SUPERVISI DI SEKOLAH DASAR PERTIWI BOGOR
}

\author{
Muhamad Ginanjar Ganeswara ${ }^{\left.a^{*}\right)}$, Nita Karmila ${ }^{\text {a) }}$ \\ a) Universitas Pakuan, Bogor, Indonesia \\ ${ }^{*}$ e-mail korespondensi: mg.ganeswara@unpak.ac.id
}

\section{Riwayat Artikel}

diterima 20 November 2021 direvisi 10 Desember 2021 disetujui 30 Desember 2021

\begin{abstract}
Abstrak.
Supervisi pendidikan merupakan hal krusial yang perlu dilakukan sebagai salah satu upaya untuk meningkatkan kualitas pendidikan yang memperhatikan seluruh komponen sumber daya organisasi. Supervisi pendidikan yang dilaksanakan secara sistematis dan berkesinambungan dapat menjadi modal untuk mengangkat citra sekolah di masyarakat. Penelitian kualitatif deskriptif yang dilakukan di SD Pertiwi Kota Bogor ini bertujuan untuk mengetahui sejauh mana implementasi supervisi pendidikan ditinjau dari elemen objek, subjek, tujuan dan waktu pelaksanaan supervisi yang tentu menggunakan berbagai macam teknik-teknik supervisi pendidikan. Sumber data primer dalam penelitian ini terdiri dari kepala sekolah, wakil kepala sekolah bidang kurikulum serta satu orang guru dan sumber data sekunder berupa dokumen-dokumen bukti pelaksanaan supervisi. Teknik pengambilan data dilakukan dengan wawancara mendalam, observasi serta analisis dokumentasi. Validasi data dilakukan dengan cara triangulasi dan member check. Penelitian diawali dengan menentukan fokus utama, sub fokus, pencarian data, reduktsi data, interpretasi data serta pengambilan kesimpulan penelitian. Hasil penelitian dapat disimpulkan bahwa SD Pertiwi Kota Bogor sudah menjalankan rangkaian kegiatan supervisi secara sitematis, terencana , dan terstruktur dengan mengimplementasikan teknik supervisi individu maupun kelompok melalui berbagai kegiatan sehingga hal tersebut menjadi modal dasar SD Pertiwi sebagai salah satu SD yang memiliki citra positif di masyarakat.
\end{abstract}

Kata Kunci: Supervisi; Sekolah Dasar

\section{THE IMPLEMENTATION OF SUPERVISION IN PERTIWI BOGOR ELEMENTARY SCHOOL}

Educational supervision is a crucial thing that needs to be done as an effort to improve the quality of education by paying attention to all components of organizational resources. Educational supervision that is carried out systematically and continuously can be an important basis to raise the image of the school in the community. This descriptive qualitative research conducted at SD Pertiwi, Bogor City, aims to determine the extent of the implementation of educational supervision in terms of object, subject, objective and time of the supervision implementation, which of course use a variety of educational supervision techniques. The primary data sources in this study consisted of the school principal, vice principal in the field of curriculum and one teacher. The secondary data sources are in the form of documents evidence of the implementation of supervision. The data collection technique was carried out by in-depth interviews, observation and documentation analysis. Data validation is done by triangulation and member check. The study begins with determining the main focus, sub focus, data search, data reduction, data interpretation and research conclusions. The results of the study concluded that Pertiwi Elementary School in Bogor City has carried out a series of systematic, planned, and structured supervision activities by implementing individual and group supervision techniques through various activities so that it becomes the basis of Pertiwi Elementary School as one of the elementary schools that has a positive image in the community.

Keywords: Supervision, Elementary School

\section{PENDAHULUAN}

Penyelenggaraan pendidikan menjadi sebuah hal dasar yang perlu terus mendapatkan perhatian dari berbagai pihak. Salah satu tolak ukur kualitas suatu negara dapat dilihat dari sejauh mana keberhasilan pendidikan dalam negara tersebut. Pentingnya memperhatikan kualitas pendidikan tidak lepas dari pengimplementasian fungsi-fungsi manajemen pendidikan mulai dari tahap planning, organizing, actuating sampai pada controling yakni pengawasan yang dilakukan oleh pihak-pihak tertentu. Sekolah Dasar menjadi salah satu pondasi awal untuk membentuk generasi yang dapat memberikan kontribusi bagi kemajuan sebuah negara. Oleh karena itu, perlu upaya yang lebih tepat untuk terus meningkatkan kualitas pendidikan khususnya pada jenjang Sekolah Dasar. Salah satu upaya tersebut yakni dengan melaksanakan supervisi atau yang lebih dikenal dengan istilah pengawasan. Supervisi pendidikan menjadi salah satu cara untuk mengetahui sejauh mana proses pendidikan berjalan dengan baik ditinjau dari keseluruhan sumber daya organisasi mulai dari man, money, method, material, machine, market dan information. Supervisi adalah suatu kegiatan yang diberikan untuk membantu guru dalam melaksanakan tugasnya dengan lebih baik. Seseorang yang melaksanakan 
supervisi disebut sebagai supervisor. Peran supervisor adalah untuk membantu, mendukung dan membagi bukan memberitahu. Supervisor yang baik harus mengembangkan kepemimpinan dalam kelompok, mengadakan kursus pelatihan dalam jabatan untuk meningkatkan keterampilan guru dan membantu guru meningkatkan kemampuannya untuk menilai hasil pekerjaan (Lele1 et al., 2018). Supervisi merupakan salah satu mekanisme dalam meningkatkan kinerja profesionalisme untuk menciptakan proses belajar siswa yang lebih baik melalui pembelajaran yang lebih baik. Selain itu, supervisi juga bertujuan untuk mengembangkan dan mencapai proses belajar mengajar yang efektif dan relevan melalui peningkatan kemampuan guru (Fahmi et al., 2018). Sedangkan Karmila dan Suchyadi (2020) menyatakan bahwa supervisi merupakan segala daya upaya yang dilakukan oleh seseorang sebagai peran aktif dan partisipatif dengan tujuan meningkatkan kualitas pendidikan dan pembelajaran melalui peningkatan kemampuan dan keterampilan guru maupun kepala sekolah. Supervisi berfungsi untuk membantu, mendukung dan mengadakan perubahan menuju perbaikan. Seseorang yang melakukan pengawasan (supervisor) dapat bertindak sebagai a) koordinator; mengkoordinasikan bawahan, b) konsultan; sebagai penampung aspirasinya bawahan, c) pemimpin kelompok; diharapkan untuk memimpin bawahan, evaluator; mengevaluasi semua kegiatan yang telah dilakukan (Wahyu, 2020). Supervisi dilaksanakan bukan hanya terhadap orangorang yang terlibat didalamnya, namun termasuk juga sarana prasarana serta hal lainnya yang sudah ditentukan dalam Standar Nasional Pendidikan (Rahabay, 2016).

Supervisi di sekolah dilaksanakan oleh kepala sekolah yang bertindak sebagai supervisor, maka ia harus mampu melakukan berbagai pengawasan dan pengendalian untuk meningkatkan kinerja guru. Pengawasan dan pengendalian merupakan tindakan preventif untuk mencegah agar guru tidak melakukan penyimpangan dan lebih berhati-hati dalam melaksanakan pekerjaannya sebagai pendidik (Maladerita, 2019). Supervisi yang dilakukan oleh kepala sekolah juga merupakan suatu usaha memberikan bantuan kepada guru untuk memperbaiki atau meningkatkan proses dan situasi pembelajaran dengan sasaran akhirnya yakni meningkatkan hasil belajar siswa (Suradi, 2018). Berdasarkan beberapa penjelasan terkait supervisi maka disimpulkan bahwa implementasi supervisi sangat penting dilaksanakan untuk meningkatkan kualitas pendidikan melalui peningkatan sumber daya organisasi yang pada akhirnya berdampak pada kualitas lulusan.

\section{METODOLOGI}

Penelitian ini merupakan penelitian kualitatif deskriptif yang bertujuan untuk menggali informasi secara mendalam terkait implementasi supervisi di Sekolah Dasar Pertiwi Bogor. Sumber data primer dalam penelitian ini terdiri dari kepala sekolah, wakil kepala sekolah bidang kurikulum serta satu orang guru. Disamping itu, dikuatkan dengan sumber data sekunder berupa dokumen-dokumen bukti pelaksanaan supervisi. Teknik pengambilan data dilakukan dengan wawancara mendalam, observasi serta analisis dokumentasi. Validasi data dilakukan dengan cara triangulasi dan member check. Penelitian diawali dengan menentukan fokus utama, sub fokus, pencarian data, reduktsi data, interpretasi data serta pengambilan kesimpulan penelitian.

\section{HASIL DAN PEMBAHASAN}

Sekolah Dasar Pertiwi merupakan salah satu sekolah swasta yang cukup terkenal di Kota Bogor. SD Pertiwi menjadi salah satu SD yang memiliki citra sekolah dengan kualitas yang baik. Citra baik yang sudah melekat menjadi salah satu hal yang menarik untuk dikaji, salah satunya dari sisi implementasi supervisi pendidikan yang dilaksanakan. Berdasarkan hasil penelitian dapat dijelaskan beberapa hal yang berkaitan dengan impelementasi supervisi mulai dari objek, subjek, tujuan, dan waktu pelaksanaan supervisi. Hasil penelitian diuraikan sebagai berikut:

\section{Objek Supervisi}

Supervisi yang ditekankan di SD Pertiwi yakni supervisi akademik. Supervisi akademik merupakan salah satu rangkain kegiatan yang bertujuan membantu guru mengembangkan kemampuan mengelola proses pembelajaran untuk mencapai tujuan pembelajaran. Dalam hal ini kepala sekolah memiliki keyakinan bahwa dengan melaksanakan supervisi akademik secara sistematis dan berkelanjutan menjadi salah satu kekuatan untuk dapat meningkatkan kualitas pembelajaran melalui peningkatan kualitas guru dalam melaksanakan tugas dan fungsinya.

Kegiatan rutin pelaksanaan supervisi diawali dengan persiapan perangkat pembelajaran yang oleh guru untuk satu minggu pembelajaran yakni berupa Rencana Pelaksanaan Pembelajaran (RPP), Lembar Kerja Peserta Didik (LKPD), soal evaluasi, hingga media pembelajaran yang akan digunakan. Terkait administrasi sekolah dilakukan pengawasan oleh kepala sekolah melalui kepala Tata Usaha (TU) sedangkan terkait sarana dan prasarana dilakukan pengawasan oleh kepala bagian tertentu, sebagai contoh perpustaan diawasi oleh kepala perpustakaan yang memiliki tanggung jawab penuh untuk mengelola keberfungsian dan jalannya sistem perpustakaan sekolah. Begitu pula dengan sarana dan prasarana lainnya yang diawasi oleh masingmasing para pengelola yang sudah ditunjuk oleh kepala sekolah. Dengan demikian, bahwa objek supervisi di SD Pertiwi bukan hanya melibatkan unsur manusianya namun juga unsur non-manusia yakni supervisi terkait sarana maupun sistem yang ada di sekolah. Hal ini menjadi salah satu kekuatan bagi SD Pertiwi untuk memberikan pelayanan yang maksimal sehingga hal ini akan memberikan kenyamanan pada seluruh sumber daya manusia pendidikan yang ada sehingga meningkatkan kualitas pembelajaran yang berdampak besar pada kualitas lulusan. Hal ini sejalan dengan hasil penelitian A. Wahib (2021) yang menyatakan bahwa pelaksanaan supervisi tidak hanya berfokus pada objek manusia namun juga non-manusia yang keduanya sama-sama perlu mendapatkan pengawasan sehingga seluruh komponen yang dilakukan pengawasan dapat menjadi barometer kualitas suatu pendidikan.

Subjek Supervisi 
Subjek supervisi di SD Pertiwi Bogor yakni dimulai dari kepala Yayasan, kepala sekolah, guru kelas, serta koordinator guru kelas rendah dan tinggi. Implementasi supervisi di SD Pertiwi dilaksanakan secara berjenjang, sistematis dan berkelanjutan, hal ini dapat dilihat dari pelaksanaan supervisi yang beruntun mulai dari supervisi yang dilakukan kepala Yayasan terhadap kepala sekolah, kepala sekolah terhadap wakil kepala sekolah, wakil kepala sekolah terhadap koordinator guru kelas, guru kelas terhadap peserta didik. Hal ini dilakukan untuk memudahkan mendapatkan informasi menyeluruh terkait rangkaian kegiatan proses pendidikan yang diselenggarakan sehingga jika terjadi hal-hal yang kurang sesuai dapat segera diambil tindak lanjut dengan sesegera mungkin.

Di samping urutan-urutan yang telah diuraikan tersebut, sejatinya bahwa kepala sekolah sebagai supervisor melaksanakan supervisi secara menyeluruh terhadap seluruh sumber daya organisasi yang ada. Kepala sekolah memberikan wewenang guru yang menjadi koordinator untuk melaksanakan tugasnya dengan tujuan untuk mempermudah kepala sekolah dalam melakukan superivisi mulai dari mengetahui permasalahan yang dialami guru kelas, peserta didik dan seluruh elemen lainnya. Koordinator guru kelas merupakan guru senior secara pengalaman dan kemampuannya sehingga dipastikan dapat memberikan informasi dan laporan kegiatan yang menunjang peningkatan kualitas pembelajaran khususnya dan hal lain pada umumnya. Kepala sekolah juga mempunyai tanggung jawab untuk melaporkan perkembangan sekolah kepada pihak Yayasan dan Dinas Pendidikan secara berkala sehingga perkembangan sekolah dapat terpantau demi peningkatan kualitas sekolah dan lulusan yang jauh lebih baik setiap tahunnya. Hal ini sejalan dengan hasil penelitian Safitri dan Mujiati (2019) yang menjelaskan bahwa efektifitas supervisi pendidikan dapat dilihat dari sejauh mana kekonsistenan alur pelaksanaan supervisi yang dilakukan oleh seluruh elemen dalam suatu sekolah.

\section{Tujuan Supervisi Pendidikan}

Supervisi yang dilaksankaan di SD Pertiwi bertujuan untuk membantu guru agar lebih mengerti kebutuhan dan masalah-masalah yang dihadapi saat proses pembelajaran berlangsung, selain itu supervisi yang dilaksanakan sebagai bentuk pelaksanaan kepemimpinan yang efektif secara demokratif untuk meningkatkan kegiatan yagn lebih baik dengan pemberian bantuan, bimbingan dan pengawasan yang dilakukan secara menyeluruh.

\section{Waktu dan Pelaksanaan Supervisi}

Implementasi supervisi pendidikan di SD Pertiwi menggunakan dua teknik yakni teknik individu dan kelompok. Teknik supervisi perseorangan meliputi kunjungan kelas, observasi kelas, supervisi teman sejawat dan konsultasi dengan senior. Dalam pelaksanaan kunjungan kelas, kepala sekolah berkunjung ke setiap kelas untuk melihat kondisi peserta didik saat proses pembelajaran. Dalam kunjungan kelas ini, kepala sekolah terlibat langsung, namun jika berhalangan kepala sekolah meminta koordinator guru untuk menggantikannya. Dalam pelaksanaan supervisi teman sejawat biasanya guru yang menemukan masalah di lapangan dapat menyampaikan keluh kesahnya kepada guru senior yang dianggap berpengalaman dan memiliki pengetahuan yang lebih untuk memberikan saran dan solusi dari permasalahan yang disampaikan.

Teknik supervisi kelompok yang dilakukan di SD Pertiwi Bogor yakni dengan melakukan rapat berkala yang diadakan seminggu sekali untuk mendengarkan hal-hal yang perlu disampaikan oleh guru sehingga semua dapat dipantau dan dilakukan tindak lanjut dengan segera jika ada permasalahan yang terjadi. Selain itu, teknik kelompok dilakukan juga dengan mengadakan workshop dengan mendatangkan ahli yang sesuai dengan kebutuhan. Hal ini dilakukan untuk terus meningkatkan kualitas pendidikan di SD Pertiwi. Menurut Riatun (2020) pelaksanaan teknik supervisi individu maupun kelompok wajib dilakukan sesuai dengan kebutuhan agar supervisi yang dilakukan tepat sasaran sehingga berdampak luas bagi kemajuan pendidikan.

\section{KESIMPULAN}

Berdasarkan hasil penelitian dinyatakan bahwa SD Pertiwi Kota Bogor telah mengimplementasikan supervisi pendidikan yang menekankan pada supervisi akademik. Namun selain itu, yang menjadi objek supervisi bukan hanya unsur manusia namun juga unsur non-manusianya termasuk supervisi sarana dan prasarana. Subjek supervisi dimulai dari kepala Yayasan, kepala sekolah, guru kelas, serta koordinator guru kelas rendah dan tinggi. Sedangkan tujuan supervisi di SD Pertiwi yaitu untuk membantu guru agar lebih mengerti kebutuhan dan masalah-masalah yang dihadapi saat proses pembelajaran berlangsung, selain itu supervisi yang dilaksanakan sebagai bentuk pelaksanaan kepemimpinan yang efektif secara demokratif untuk meningkatkan kegiatan yagn lebih baik dengan pemberian bantuan, bimbingan dan pengawasan yang dilakukan secara menyeluruh. Supervisi dilaksanakan dengan menerapkan teknik supervisi individu dan kelompok yang dilakukan secara terjadwal melalui berbagai kegiatan yang menunjang peningkatan kualitas pendidikan.

\section{REFERENSI}

A. Suradi, (2018) "Supervisi Akademik Kepala Sekolah Terhadap Kinerja Guru Pendidikan Agama Islam Di Sekolah Dasar Negeri 79 Kota Bengkulu" AULADUNA: Jurnal Pendidikan Dasar Islam Vol. 5 No. 1, pp. 13-29.

Abd. Wahid, (2021)“ Manajemen Evaluasi Program Supervisi Pendidikan Dalam Meningkatkan Mutu Pendidikan" Jurnal Auladuna: Jurnal Pendidikan Dasar Islam, Vo. 8 No. 1.

Apriani Safitri, Mujiati Mujiati, (2019) “Efektivitas Supervisi Akademik Kepala Sekolah", Didaktis: Jurnal Pendidikan dan Ilmu Pengetahuan, Volume 19, No. 1.

David Moto Lele1, Deni Setiawan , Sulhadi, (2018) Clinical Supervision Instrument Development for Junior High School Teacher Based on Android, Journal of Educational Research and Evaluation. JERE 7 (1) 94 100. 
Fahmi, Cut Nurul, Eli Nurliza, Murniati AR, Nasir Usman, (2018) The Analisys of Supervision Perception at The Elementary School Aceh Besar Indonesia. The International Journal of Social Sciences and Humanities Invention. Vol. 5. No. 8.

Nita Karmila, Yudhie Suchyadi, (2020) "Supervisi Pendidikan di Sekolah Alam Bogor" Jurnal Pendidikan dan Pengajaran Guru Sekolah Dasar. Volume 03, Nomor 01, Hal. 31 - 33

Patris Rahabav, (2016) The Effectiveness of Academic Supervision for Teachers, Journal of Education and Practice, Vol.7, No.9, pp. 47-49.

Riatun, (2020) "Pelaksanaan Teknik Supervisi Individual sebagai Implementasi Kerja Pengawasan", EJoES: Educational Journal of Elementary School. Vol. 1 No. 3.

Wahyu, (2020) Concept Of Supervision Of Learning Process In Increasing The Quality Of Education Results In Madrasah, International Journal of Nusantara Islam Vol. 08 No. 01: (67-77) DOI : 10.15575/ijni.v8i1.8913.

Wiwik Maladerita, Dina Dahliana, Maistika Ratih, Rifma. (2019) "Impelementasi Supervisi dalam Meningkatkan Proses Pembelajaran dan Pendidikan Karakter di Sekolah Dasar" Edukatif : Jurnal Ilmu Pendidikan Volume 1 Nomor 3 Halaman 198-204 